\title{
Temporal changes in Egr-1 and c-fos expression in rat models of myocardial ischemia
}

\author{
Li-Qin Zhai ${ }^{1 \#}$, Xiang-Jie Guo ${ }^{2 \#}, \mathrm{Ze} \mathrm{Li}^{2}$, Run-Feng Sun ${ }^{2}$, Qian-Qian Jin ${ }^{2}$, Ming-Zhe Liu ${ }^{2}$, Hua-Lin Guo ${ }^{2}$, \\ Cai-Rong Gao ${ }^{2}$
}

${ }^{1}$ Department of Pathology, Shanxi Provincial People's Hospital, Taiyuan, China; ${ }^{2}$ Department of Pathology, School of Forensic Medicine, Shanxi Medical University, Taiyuan, China

Contributions: (I) Conception and design: CR Gao, LQ Zhai, XJ Guo; (II) Administrative support: CR Gao, XJ Guo; (III) Provision of study materials or patients: LQ Zhai, Z Li; (IV) Collection and assembly of data: LQ Zhai, Z Li, RF Sun, QQ Jin, MZ Liu, HL Guo; (V) Data analysis and interpretation: CR Gao, LQ Zhai, XJ Guo; (VI) Manuscript writing: All authors; (VII) Final approval of manuscript: All authors.

"These authors contributed equally to this work.

Correspondence to: Cai-Rong Gao. Department of Pathology, School of Forensic Medicine, Shanxi Medical University, No. 29 of Jiefangnan Road, Yingze District, Taiyuan 030001, China. Email: drgaocr99@163.com.

Background: The pathological diagnosis of sudden cardiac death caused by myocardial ischemia is a difficult problem. Relevant evidence shows that the expression of Egr-1 and c-fos undergo changes in the early stage of myocardial ischemia, but the detailed temporal variation of them is not clear. Therefore, the aim of this study was to observe the temporal changes in mRNA and protein expression of Egr-1 and c-fos in ischemic myocardium in rats.

Methods: Sixty-six Sprague-Dawley rats were divided into the control group, the early myocardial ischemia (EMI) group, the sham operated group and the allergy group. The EMI rats were further divided into eight subgroups according to the different time points (30 min and 1, 2, 4, 8, 12, 24, and $48 \mathrm{~h}$ ) after modeling. The mRNA and protein of Egr-1 and c-fos of each group were detected by real-time quantitative polymerase chain reaction and immunohistochemistry, respectively.

Results: In the EMI group, Egr-1 mRNA in ischemic myocardium rose 30 min after ischemia and peaked at $2 \mathrm{~h}$; the plateau was maintained up to $8 \mathrm{~h}$ after ischemia, and then returned to the baseline level at $12 \mathrm{~h}$. The c-fos mRNA in ischemic myocardium demonstrated a consistent changing curve with that of Egr-1. The mRNA of Egr-1 and c-fos showed no significant changes in the control group, the sham operated group and the allergy group. Immunohistochemistry showed that Egr-1 protein in the myocardial ischemic area was slightly positive $30 \mathrm{~min}$ after ischemia, and then strongly positive at 4 and $8 \mathrm{~h}$, decreased at $12 \mathrm{~h}$, and was negative at $24 \mathrm{~h}$. The changing trends of c-fos protein were almost the same as that of Egr- 1 . Immunohistochemistry of Egr-1 and c-fos protein were all negative in the control group, the sham operated group and the allergy group.

Conclusions: The mRNA and protein expression of Egr-1 and c-fos presented rapid and temporal changes after myocardial ischemia, and this may be helpful in distinguishing sudden death induced by myocardial ischemia from that of allergy.

Keywords: Egr-1; c-fos; sudden death; early myocardial ischemia; allergy

Submitted Jan 06, 2020. Accepted for publication Aug 04, 2020.

doi: 10.21037/apm-20-89

View this article at: http://dx.doi.org/10.21037/apm-20-89 


\section{Introduction}

The identification of sudden cardiac death is frequently performed in forensic practice. However, in some cases where sudden death has occurred, only coronary artery stenosis is found and there is no clear pathomorphological evidence of myocardial ischemia, also known as "sudden coronary death". In such cases, the diagnosis of sudden cardiac death is a challenge, especially when the deceased has a history of medication before death. It is difficult to identify the exact cause of death, because sudden cardiac death is particularly hard to distinguish from sudden allergic death in such a situation.

Both Egr-1 and c-fos are members of the immediate early gene (IEGS) family and can be rapidly up-regulated after stimulation. Egr-1 protein participates in many physiological processes such as cell growth, differentiation, and proliferation and in matrix remodeling. In addition, it plays a role in many pathological processes. It helps to maintain the stability of the intracellular environment by regulating the expression of multiple downstream target genes. Tissue or cellular hypoxia is a major trigger of $E g r-1$ gene expression. Studies have confirmed that Egr-1 protein expression is enhanced after ischemia/reperfusion in lungs (1) and kidneys (2). In terms of expression and diagnostic value of c-fos in rat models of EMI, c-fos is a protooncogene involved in the growth and development of the cardiovascular system. Massive c-fos expression occurs during the embryonic period, and the gene transcription markedly decreases and even disappears after birth. Little or no c-fos is expressed in adult cardiomyocytes.

Previous studies have found that Egr- 1 and c-fos protein expression increases during myocardial ischemia/reperfusion injury. However, it is unclear whether the expression of these two genes change during EMI and if they are helpful to diagnose sudden death due to EMI without obvious pathomorphological changes. To address these issues, we observed the temporal changes in the expression of Egr1 and c-fos in rat models of EMI based on bioinformatics analysis.

We present the following article in accordance with the STROBE Reporting Checklist (available at http://dx.doi. org/10.21037/apm-20-89).

\section{Methods}

\section{Reagents and equipment}

The main reagents used in this study included Trizol reagent (Invitrogen, Carlsbad, California, USA), Revert Aid RT reverse transcription kit (Thermo Fisher, Waltham, Massachusetts, USA), SYBR ${ }^{\circledR}$ Green PCR master mix (Thermo Fisher, Waltham, Massachusetts, USA), rabbit anti-Egr-1 antibody ab55160 (Abcam, Cambridge, UK), and rabbit anti-c-fos antibody ab209794 (Abcam, Cambridge, UK). The equipment used included a BL-420S biological function detector (TME Technology, Chengdu, China), TC1000-S conventional PCR machine (DLAB Scientific, Beijing, China), 7500 FAST real-time PCR machine (ABI, Carlsbad, California, USA), and a RM2245 slicer (Leica, Solms, Germany).

\section{Experimental animals}

Clean male Sprague-Dawley (SD) rats (aged 10-12 weeks and weighing 200-220 g) were provided by the Experimental Animal Center of the Fuwai Hospital of Chinese Academy of Medical Sciences (Beijing, China).

\section{Experimental methods}

\section{Grouping}

Sixty-six SD rats were randomly divided into the normal control group (Control group, $n=6$ ), the EMI group ( $n=48$ ), the sham operated group (Sham group, $n=6$ ) and the sudden death induced by allergy group (Allergy group, $n=6$ ). In the EMI group, the rats were further divided into eight subgroups (EMI1, EMI2, EMI3, EMI4, EMI5, EMI6, EMI7, and EMI8, $n=6$ in each group) according to the different time points (30 min, 1, 2, 4, 8, 12, 24, and $48 \mathrm{~h}$ ) at which the animals were sacrificed after modeling.

\section{Establishment of rat models of EMI}

SD rats were routinely disinfected and anesthetized, and underwent orotracheal intubation. After the rats were successfully intubated, a small animal ventilator was applied, with a tidal volume of $3 \mathrm{~mL} / 100 \mathrm{~g}$, respiratory rate of 60 breaths/min, and a respiratory quotient of 1:1. The limbs were connected to the leads of the BL-420S biological function detector to acquire electrocardiographic data. According to a previous report (3), the skin was cut longitudinally $1 \mathrm{~cm}$ to the left of the midline of the sternum; the subcutaneous tissue and muscle layer were bluntly separated at the spot where the heartbeat was the strongest, between the 4th and 5 th ribs. The bilateral chest walls were pressed to eject the heart. After the left atrial appendage was lifted, the left anterior descending (LAD) coronary 
Table 1 Primers of Egr-1 and c-fos

\begin{tabular}{lccc}
\hline Genes & Primer ID & Primer sequence (5'-3') \\
\hline Beta-actin & rACTB-F & $5^{\prime}$-TGTTACCAACTGGGACGACA-3' & Product length \\
& rACTB-R & $5^{\prime}$-CTGGGTCATCTTTCACGGT-3' \\
c-fos & CFOS-F & $5^{\prime}$-ATGCCCCTCAACGTGAACTTC-3' \\
& CFOS-R & $5^{\prime}$-GTCGCAGATGAAATAGGGCTG-3' \\
Egr-1 & Egr1-F & $5^{\prime}$-CCTATGAGCACCTGACCACA-3' \\
& Egr1-R & 5'-TCGTTGGCTGGGATAACTC-3' \\
\hline
\end{tabular}

artery was ligated with a 7-0 suture at the point about 3-4 $\mathrm{mm}$ away from aortic root between the pulmonary cone and left atrial appendage. The needling was about $1.5 \mathrm{~mm}$ deep and $2 \mathrm{~mm}$ wide. After knotting and suturing, the thoracic cavity was closed and the endotracheal tube was withdrawn. According to the literature (4), the modeling of EMI in rats was considered successful if at least one of the following conditions was met: (I) ST segment elevation $\geq 0.1 \mathrm{mv}$; (II) upright $\mathrm{T}$ wave that exceeds $50 \%$ of the height of the $\mathrm{R}$ wave of the same lead; the color of the myocardium under the ligation site of the anterior $\mathrm{LV}$ wall changed from pink to pale, as observed by the naked eye.

Food and water were routinely administered to the animals after surgery. According to experimental design, the rats were sacrificed by cervical vertebral dislocation and the heart was removed. The heart was then washed with normal saline, and the myocardial ischemic area in the anterior wall of the left ventricle (LV) was obtained below the plane of the coronary artery ligation point. One half of the myocardial ischemic area was preserved in liquid nitrogen and the other half was fixed in 10\% neutral buffered formalin.

In the Sham group, the suture only passed through the myocardial tissue without ligating the coronary artery, and the remaining experimental steps were the same as above.

\section{Establishment of rat models of sudden death due to allergy}

Rat models of sudden death due to allergy were established according to a previous report (5). On the first day of the experiment, the rats were intraperitoneally injected with $5 \%$ chicken ovalbumin $(0.8 \mathrm{~mL})$ and $4 \%$ aluminum hydroxide adjuvant $(0.5 \mathrm{~mL})$ for sensitization. On the 18 th day of the experiment, $2 \mathrm{~mL}$ of $2 \%$ chicken ovalbumin was injected into the tail vein to induce anaphylaxis. Myocardial tissue was harvested from the anterior left ventricular wall. Following the same treatments as above, the samples were preserved for further experiments.

\section{Quantitative real-time polymerase chain reaction (qRT- PCR)}

Total RNA was extracted from myocardial tissue to synthesize cDNA by reverse transcription. Primers were designed and synthesized (Table 1). PCR amplification was performed according to the manufacturer's instructions. The conditions were as follows: pre-denaturation at $95{ }^{\circ} \mathrm{C}$ for $5 \mathrm{~min}$, followed by 40 cycles of denaturation at $95^{\circ} \mathrm{C}$ for $10 \mathrm{~s}$ and annealing and extension at $60^{\circ} \mathrm{C}$ for 30 s. Following amplification, the temperature of the reaction system was gradually increased by $1{ }^{\circ} \mathrm{C}$ every $5 \mathrm{~s}$ from $60^{\circ} \mathrm{C}$ to $95^{\circ} \mathrm{C}$, and the melting curve of the PCR product was analyzed.

\section{Immunohistochemical staining of rat myocardial tissue} Rat myocardial tissue was fixed in $10 \%$ neutral formalin for $24 \mathrm{~h}$, and multiple blocks were sampled along the horizontal plane and embedded in paraffin. The blocks were then cut

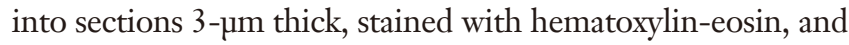
observed under a light microscope. In addition, sections of $2-\mu \mathrm{m}$ thick were obtained, and then immunohistochemical staining with anti-c-fos and anti-Egr-1 monoclonal antibodies was performed using the EnVision two-step procedure. Each stained section was scored according to a previous report (6). The scoring criteria were as follows: the percentage of positive cells (A) and the staining intensity (B) was evaluated respectively. A: the percentage of positive cells was scored using the following numeric system: 0 (no positive cells); $1(1-10 \%) ; 2$ (11-50\%); 3 (51-80\%); and $4(81-100 \%)$. B: staining intensity: 0 (absence of staining), 1 (weak staining), 2 (moderate staining), and 3 (strong staining). Finally, $\mathrm{A} \times$ $\mathrm{B}$ was used as a comprehensive score, with a score range of $0-12$ points, of which $0-1$ was negative staining (-), 2-3 was weak staining $(+), 4-6$ was positive staining $(++)$, 


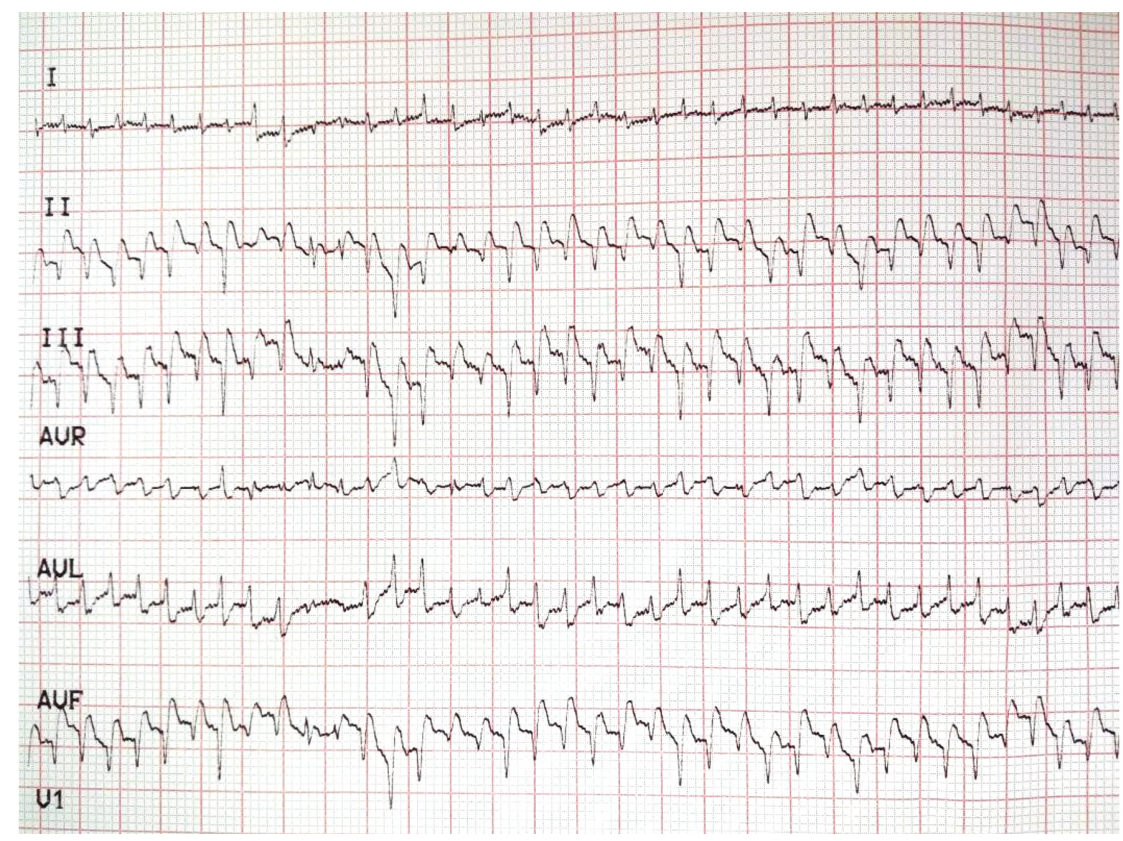

Figure 1 Electrocardiogram of SD rats after LAD coronary artery ligation. LAD, left anterior descending.

7-9 was moderate staining $(+++)$, and 10-12 was strong staining $(++++)$.

\section{Statistical analysis}

The experimental data were analyzed using SPSS 20.0 software. The measurement data that met the requirements of parametric tests are presented by mean \pm standard deviations (mean $\pm \mathrm{SD}$ ); comparisons of these data among multiple groups were performed using univariate analysis of variance, and the LSD test was applied for comparisons between the two groups. Measurement data that did not meet the requirements of parametric tests and ordered categorical data were analyzed using the Kruskal-Wallis $\mathrm{H}$ test. A P value of $<0.05$ was considered statistically significant.

The study protocol was carried out according to the Declaration of Helsinki (as revised in 2013). The research project was approved by the Ethics Committee of the Shanxi Provincial People's Hospital (No. 0000630). All applicable international, national, and/or institutional guidelines for the care and use of animals were followed.

\section{Results}

\section{Rat models of EMI}

In the EMI group, the ST segment climbed upwards and/or the $\mathrm{T}$ wave became upright and sharp shortly after ligation; in some rats the $\mathrm{T}$ waves and $\mathrm{R}$ waves were fused together (Figure 1). These changes were not observed in all six rats in the Sham group. During ligation of the LAD artery, 13 rats in the EMI group and 2 rats in the Sham group showed transient $\mathrm{Q}$ wave changes (widened and deepened $\mathrm{Q}$ waves) after the surgical suture was passed through the myocardial tissue. However, these changes returned to normal within a few seconds.

\section{Rat models of sudden death due to allergy}

In the Allergy group, six SD rats showed agitation, piloerection, scratching, and cyanotic lips within 3-7 min of the antigen challenge, and developed anaphylaxis symptoms including dyspnea, nasal flaring and standing instability within $12-15 \mathrm{~min}$. Three rats died within $30 \mathrm{~min}$ and the other three remained alive.

\section{Results of $q R T-P C R$}

Compared with the control group, Egr-1 mRNA in the myocardial tissue of the anterior $\mathrm{LV}$ wall was not significantly increased in the Allergy group and the Sham group (P>0.05, Figure 2). In the EMI1 group, Egr-1 mRNA in the ischemic myocardial tissue was significantly increased 


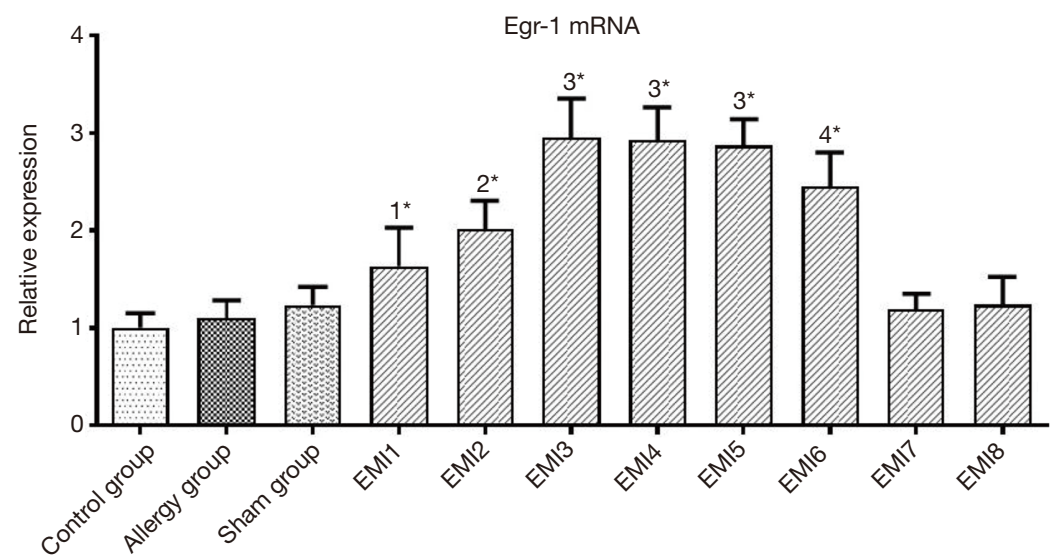

Figure 2 Relative mRNA expression level of Egr-1 in the myocardium of the LV anterior wall in different groups. $1^{*}$, significantly stronger than that in the control group $(\mathrm{P}<0.05)$. $2^{*}$, significantly stronger than that in the control group, EMI1 group, and EMI2 group ( $\left.<<0.01\right)$. $3^{*}$, significantly stronger than that in the control group, EMI1 group, EMI2 group, and EMI3 group (all P<0.01). 4*, significantly weaker than that in the EMI4 group and EMI5 group (both $\mathrm{P}<0.01$ ), but still significantly stronger than that in the control group, EMI1 group, and EMI2 group $(\mathrm{P}<0.05)$.

compared with that of the control group $(\mathrm{P}<0.01$, Figure 2$)$. In the EMI2 group, Egr-1 mRNA in the ischemic myocardial tissue was further increased and significantly higher than that of the EMI1 group $(\mathrm{P}<0.05$, Figure 2). In the EMI3 group, Egr-1 mRNA in the ischemic myocardial tissue was further increased and significantly higher than that of the EMI2 group $(\mathrm{P}<0.01$, Figure 2). In the EMI4 and EMI5 groups, Egr-1 mRNA in the ischemic myocardial tissue showed no significant difference $(\mathrm{P}>0.05$, Figure 2$)$ and was not significantly different from that of the EMI3 group (both $\mathrm{P}>0.05$, Figure 2). Therefore, Egr-1 mRNA in the myocardial ischemic area reached a peak at $2 \mathrm{~h}$ and the plateau was maintained up to $8 \mathrm{~h}$ after ischemia. In the EMI6 group, Egr-1 mRNA in the ischemic myocardial tissue was significantly lower than that of the EMI3, EMI4, and EMI5 groups (all $\mathrm{P}<0.05$, Figure 2), but was still significantly higher than that of the EMI2 group $(\mathrm{P}<0.05$, Figure 2). In the EMI7 and EMI8 group, Egr-1 mRNA in the ischemic myocardial tissue markedly decreased and was significantly lower than that of the EMI1, EMI2, EMI3, EMI4, EMI5, and EMI6 groups, and was not significantly different from that of the control group $(\mathrm{P}>0.05$, Figure 2$)$.

Compared with the control group, c-fos mRNA in myocardial tissue of the anterior $\mathrm{LV}$ wall was not significantly increased in the Allergy group and the Sham group ( $\mathrm{P}>0.05$, Figure 3). In the EMI1 group, $\mathrm{c}-$ fos mRNA in the ischemic myocardial tissue was increased but was not significantly different compared with that of the control group $(\mathrm{P}<0.05$, Figure 3$)$. In the EMI2 group, $\mathrm{c}-$ fos mRNA in the ischemic myocardial tissue was markedly increased and was significantly higher than that of the control group and EMI1 group (both $\mathrm{P}<0.01$, Figure 3). In the EMI3 group, c-fos mRNA in the ischemic myocardial tissue was further increased and was significantly higher than that of the EMI2 group $(\mathrm{P}<0.01$, Figure 3). In the EMI4 and EMI5 groups, c-fos mRNA in the ischemic myocardial tissue was not significantly different compared with that in the EMI3 group (both $\mathrm{P}>0.05$, Figure 3), but was significantly higher than that of the EMI2 group (both $\mathrm{P}<0.01$, Figure 3). Thus, c-fos mRNA in the ischemic myocardial tissue reached a peak at $2 \mathrm{~h}$, which was maintained for up to $8 \mathrm{~h}$. In the EMI6 group, c-fos mRNA in the ischemic myocardial tissue was significantly lower than that of the EMI3, EMI4, and EMI5 groups (all $\mathrm{P}<0.01$, Figure 3), but was still significantly higher than that of the EMI2 group $(\mathrm{P}<0.05$, Figure 3). In the EMI7 and EMI8 group, c-fos mRNA in the ischemic myocardial tissue further decreased and was significantly lower than that of the EMI2, EMI3, EMI4, EMI5, and EMI6 groups, and was not significantly different from that of the control group $(\mathrm{P}>0.05$, Figure 3$)$.

\section{Results of immunobistochemical staining}

\section{Immunohistochemical staining of Egr-1 in the} myocardium of the anterior $\mathbf{L V}$ wall in each group

In the control group, Allergy group and Sham group, no brown-yellow granules were found in the nuclei of cardiomyocytes on the anterior LV wall (Figure $4 A$ ). In the 


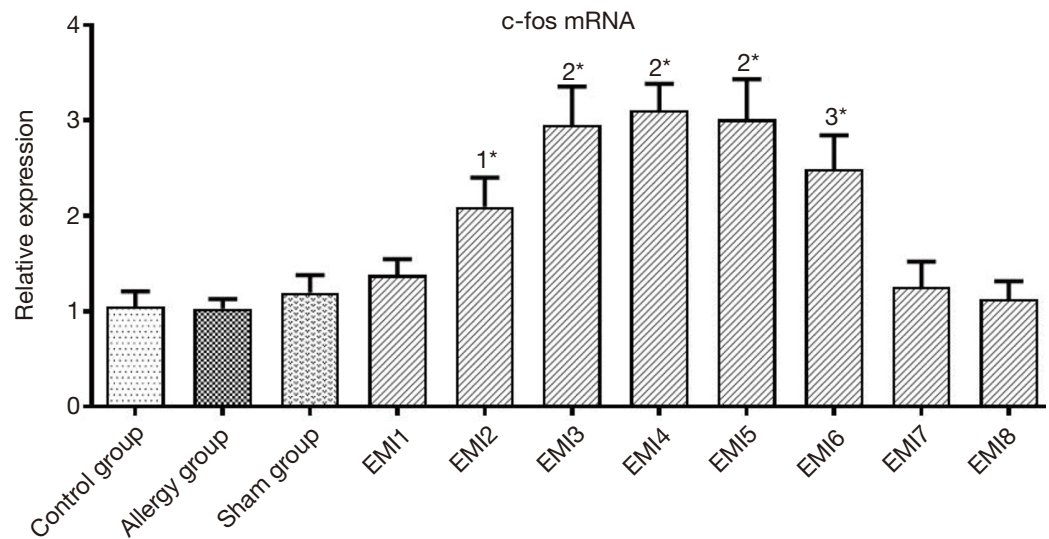

Figure 3 c-fos in the myocardium of the LV anterior wall in different groups. Relative mRNA expression level of c-fos in the myocardium of the LV anterior wall in different groups. $1^{*}$, significantly stronger than that in the control group and EMI1 group $(\mathrm{P}<0.01) .2^{*}$, significantly stronger than that in the control group, EMI1 group, EMI2 group, and EMI3 group (all $\mathrm{P}<0.01)$. $3^{*}$, significantly weaker than that in the EMI4 and EMI5 groups (both $\mathrm{P}<0.01$ ), but significantly higher than that in the control group and EMI1 group (both $\mathrm{P}<0.05$ ).

EMI group, brown-yellow granules appeared in the nuclei of cardiomyocytes in the ischemic area, in the EMI1 and EMI2 groups, light brown-yellow granules appeared in the nuclei of a small number of cardiomyocytes (Figure 4B); In the EMI3 group, the number of positive cells further increased (Figure 4C); In the EMI4 and EMI5 groups, strongly stained brown-yellow granules appeared in most cardiomyocytes (Figure 4D); In the EMI6 group, light brown-yellow granules were still visible in the nuclei of some cardiomyocytes; In the EMI7 and EMI8 groups, the proportion of positive cells was very low (Figure 4E). The results of staining score showed that negative staining of Egr-1 was observed in the control group, Allergy group and Sham group. In the EMI group, the staining score increased with ischemia time at the beginning. After the score had peaked, it decreased with ischemia time and finally became negative. In the EMI1 and EMI2 groups, the staining intensity was weak $(\mathrm{P}<0.05)$. In the EMI3 group, the staining intensity increased $(\mathrm{P}<0.01)$. In the EMI4 and EMI5 groups, the staining intensity further increased $(\mathrm{P}<0.01)$. In the EMI6 group, the positive staining weakened; In the EMI7 and EMI8 groups, the staining of ischemic area were negative (Figure $4 F$ ).

\section{Immunohistochemical staining of c-fos in the myocardium of the anterior $\mathbf{L V}$ wall in each group}

In the control group, Allergy group and Sham group, no brown-yellow granules were visible in the nuclei of cardiomyocytes on the anterior LV wall (Figure $5 A$ ). In the EMI group, brown-yellow granules appeared in the nuclei of cardiomyocytes in the ischemic area. In the EMI1 group, no clear brown-yellow granules were seen in the nuclei of cardiomyocytes in the ischemic area. In the EMI2 group, light brown-yellow granules appeared in the nuclei of a small number of cardiomyocytes (Figure $5 B$ ). In the EMI3 group, the number of positive cells further increased (Figure 5C). In the EMI4 and EMI5 groups, strongly stained brown-yellow granules appeared in most cardiomyocytes (Figure 5D). In the EMI6 group, brown-yellow granules were still visible in the nuclei of some cardiomyocytes. In the EMI7 and EMI8 groups, light brown-yellow granules were observed in only a few number of cardiomyocytes (Figure 5E). The results of staining score showed that negative staining of c-fos was observed in the control group, Allergy group and Sham group, the staining intensity in the EMI group increased with ischemia time. After the staining intensity had peaked, the positive staining decreased with ischemia time and finally, became negative. Compared with the EMI1 group, the staining intensity in the EMI2 and EMI3 groups increased respectively $(\mathrm{P}<0.01)$. In the EMI4 and EMI5 groups, the staining intensity peaked. In the EMI6 group, positive staining in the nuclei of cardiomyocytes in the ischemic area was weaker $(\mathrm{P}<0.05)$. In the EMI7 and EMI8 groups, staining was negative in the nuclei of cardiomyocytes in the ischemic area (Figure $5 F$ ). 

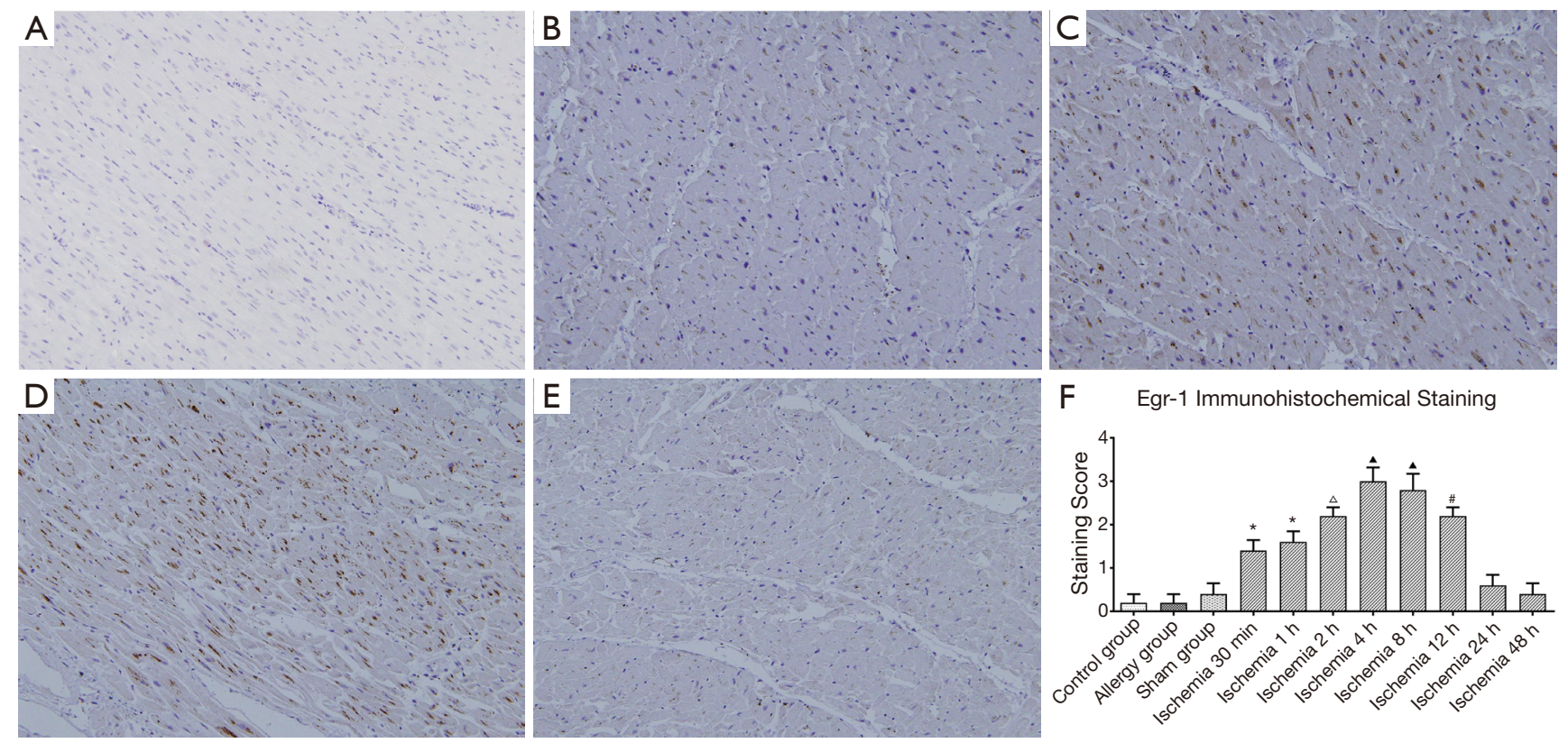

Figure 4 Immunohistochemical staining of Egr-1 in the myocardium of the anterior LV wall in each group. (A) Immunohistochemical staining of Egr-1 in the myocardium of the anterior LV wall in the control group (20x). (B) Immunohistochemical staining of Egr-1 in the myocardium of the anterior LV wall in the EMI1 group (40×). (C) Immunohistochemical staining of Egr-1 in the myocardium of the anterior LV wall in the EMI3 group (40x). (D) Immunohistochemical staining of Egr-1 in the myocardium of the anterior LV wall in the EMI4 group (20x). (E) Immunohistochemical staining of Egr-1 in the myocardium of the anterior LV wall in the EMI7 group (20x). (F) Immunohistochemical staining of Egr-1 in the myocardium of the anterior LV wall in each group. $1^{*}$, significantly stronger than that in the control group $(\mathrm{P}<0.05) .2^{*}$, significantly stronger than that in the control group, EMI1 group, and EMI2 group $(\mathrm{P}<0.01) .3^{*}$, significantly stronger than that in the control group, EMI1 group, EMI2 group, and EMI3 group (all $\mathrm{P}<0.01)$. $4^{*}$, significantly weaker than that in the EMI4 group and EMI5 group (both $\mathrm{P}<0.01$ ), but still significantly stronger than that in the control group, EMI1 group, and EMI2 group $(\mathrm{P}<0.05)$.

\section{Discussion}

Egr-1 is a transcription factor with three zinc-finger structures. It can couple the stimulation signals of various extracellular environments such as hypoxia, oxidative stress, mechanical damage and cytokines with complex biological reactions of the body by inducing its target genes (7). It plays a central regulatory role in the pathological process of tissue injury caused by ischemia by coordinating the expression of various injury factors, and becomes a molecular switch to start ischemic injury (8). After the activation of ischemia, Egr-1 can activate a series of genes related to inflammation, coagulation and vascular permeability. Egr-1 can also bind to the binding site of its own gene promoter and down regulate its own gene transcription, thus forming a negative feedback regulation on Egr-1 biosynthesis. Because of this negative feedback regulation, Egr-1 is rapidly induced by a variety of stimuli, but also under close monitoring. Egr-1 is sharply increased for a short time and can not be maintained for a long time. Therefore, Egr-1 mainly plays its longterm effect by activating its target gene (9). In the present study, Egr-1 mRNA in the myocardial ischemic area rapidly increased after early myocardial ischemia; and peaked quickly. The plateau was maintained for several hours and then rapidly decreased to the baseline level. Egr-1 mRNA and protein expression did not increase in myocardial tissue in the Allergy group. In some studies (10-12), RTPCR and western blotting showed that the mRNA and protein expression of Egr-1 in cardiomyocytes significantly increased after ischemia/hypoxia-reperfusion in rat hearts and cultured cardiomyocytes. Furthermore, an Egr-1 protein antagonist significantly attenuated the increase in Egr-1 mRNA and protein expression in cardiomyocytes after ischemia/hypoxia-reperfusion and markedly alleviated myocardial injury caused by ischemia/hypoxia-reperfusion (13-15). Egr-1 is involved in ischemia-induced myocardial 

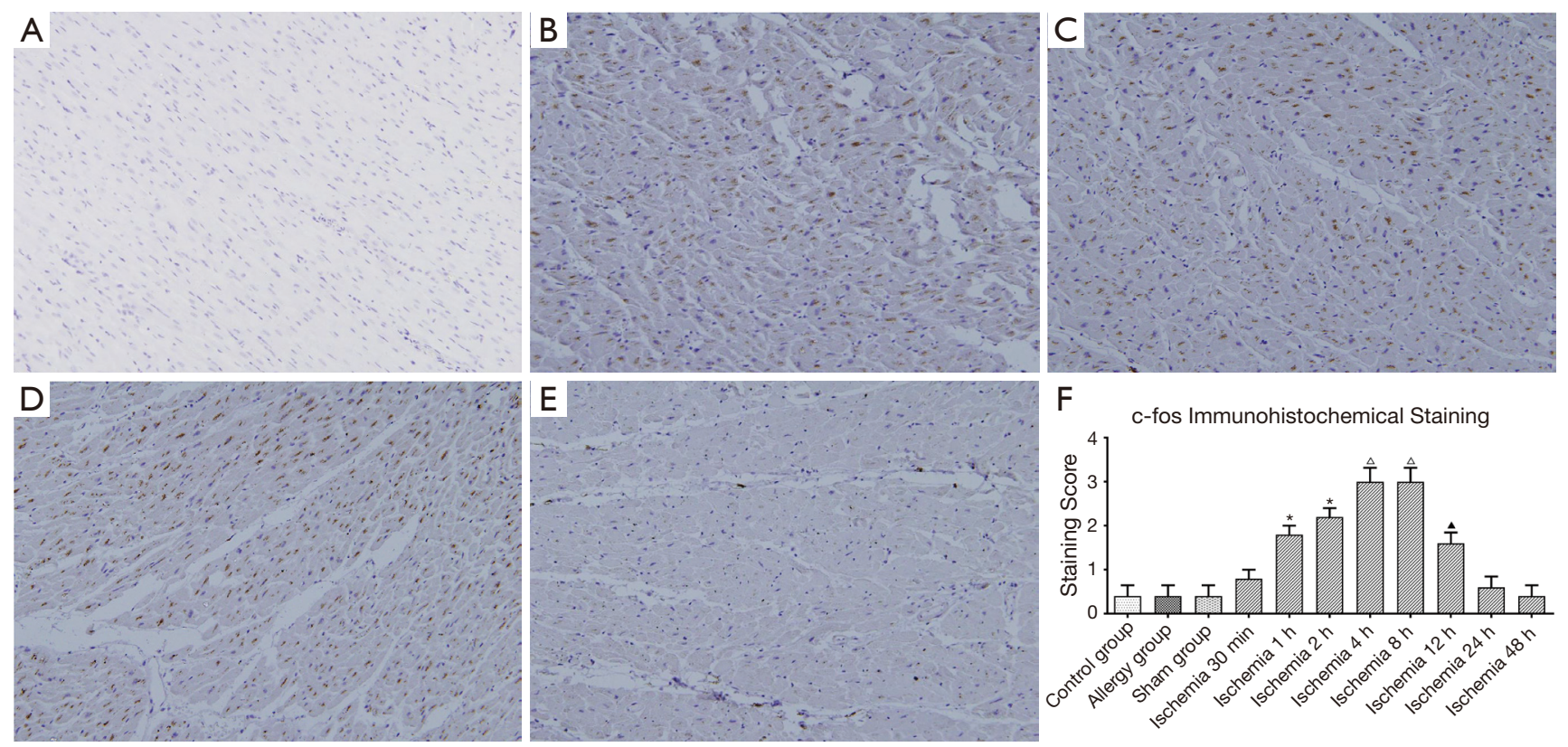

Figure 5 Immunohistochemical staining of c-fos in the myocardium of the anterior LV wall in each group. (A) Immunohistochemical staining of c-fos in the myocardium of the anterior LV wall in the control group (20x). (B) Immunohistochemical staining of c-fos in the myocardium of the anterior LV wall in the EMI2 group (40x). (C) Immunohistochemical staining of c-fos in the myocardium of the anterior LV wall in the EMI3 group (20x). (D) Immunohistochemical staining of c-fos in the myocardium of the anterior LV wall in the EMI4 group (20x). (E) Immunohistochemical staining of c-fos in the myocardium of the anterior LV wall in the EMI7 group (20x). (F) Immunohistochemical staining of c-fos in the myocardium of anterior LV anterior wall in each group. $1^{*}$, significantly stronger than that in the control group and EMI1 group $(\mathrm{P}<0.01) .2^{*}$, significantly stronger than that in the control group, EMI1 group, EMI2 group, and EMI3 group (all $\mathrm{P}<0.01$ ). $3^{*}$, significantly weaker than that in the EMI4 and EMI5 groups (both $\mathrm{P}<0.01$ ), but significantly higher than that in the control group and EMI1 group (both $\mathrm{P}<0.05$ ).

injuries and serves as a master switch in the pathological process (16). Therefore, the detection of Egr-1 mRNA and protein expression may be helpful to distinguish between sudden death due to EMI and sudden death due to allergy.

$\mathrm{C}$-fos gene exists in normal myocardium, vascular smooth muscle and endothelial cells, which is essential for the growth and development of cardiovascular system and stress response (17) and plays a certain role in stress and cell protection (18). Its expression and changes are related to the occurrence and development of a variety of cardiovascular diseases. When myocardial ischemia occurs, the protein synthesis in cardiomyocytes is inhibited, which stimulates the super induction of c-fos gene to activate the transcription of other late acting genes, thus playing a cytoprotective role (19). In most cases, the transcription of c-fos gene starts within 5 minutes after the cells are stimulated, and then the protein synthesis is carried out. After translation, c-fos protein is transferred from cytoplasm to human nucleus, which mainly binds to c-jun form heterodimer and binds to specific site on DNA to initiate the expression of target gene. Therefore, c-fos plays an important role in the nuclear "third messenger" in the process of signal transmission from external stimulation to transcription coupling (20). Under normal conditions, the IEGS c-fos was expressed in low level. It is involved in the physiological processes of myocardial cell growth, reproduction, differentiation and signal transmission (19). However, after a short period of myocardial ischemia, although the structure of ischemic cardiomyocytes did not change significantly, these cells are actually inactivated and can not produce c-fos again, so the expression level of c-fos decreased to normal (21). In our results, c-fos mRNA in the ischemic myocardial tissue rapidly increased and reached a peak at $2 \mathrm{~h}$ after myocardial ischemia, which maintained up to $8 \mathrm{~h}$ after ischemia, and then decreased rapidly and returned to baseline level. Our results suggested that c-fos mRNA and protein changed similar to Egr-1.

The $c$-fos gene and its protein are involved in the 
development of ischemia/reperfusion injury of different organs and tissue. It may play an important role in this pathological process. In one study concerning brain tissue ischemia (22), immunohistochemical staining showed that c-fos protein expression enhanced in the nuclei of neurons in the ischemic area. In another research of ischemic brain injury (23), western blot analysis demonstrated a significant increase after ischemia and a remarkable decrease in c-fos expression after treatment. Genome-wide gene expression has shown that c-fos was a commonly up-regulated gene after ischemia-reperfusion injury in kidneys, intestines, skeletal muscles and spinal cords in animal models (24-26). In a different experiment of intestinal ischemia (27), immunohistochemical analyses exhibited a temporal expression pattern of c-fos. Some researchers (28) found that $\mathrm{c}-\mathrm{fos}$ protein expression in the cardiomyocytes in the ischemic area increased in rat models of myocardial ischemia by immunohistochemistry and in situ hybridization, whereas the infarct size decreased after intervention with c-fos monoclonal antibody. Based on these findings, c-fos mRNA and protein level may be helpful in distinguishing between sudden death due to EMI with subtle morphological changes and sudden cardiac death due to allergy.

While it should be pointed out that the present study was performed under strict experimental conditions, there is still a long way to go before these two markers can be applied to forensic pathology. Studies with a more sophisticated design are required to investigate whether Egr-1 and c-fos protein are affected by post-mortem degradation and storage conditions. In addition, whether other stimuli can cause changes in the transcription and expression of Egr-1 and $\mathrm{c}$-fos in the myocardium needs further study. Whether Egr-1 and c-fos are transcribed and expressed in the periischemic regions requires more research too.

In conclusion, our results suggest that the expression of Egr-1 and c-fos presented rapid and temporal changes after myocardial ischemia, and this may be helpful in distinguishing sudden death induced by myocardial ischemia from that by allergy. However, further study is required to explore the affecting factors of Egr-1 and c-fos.

\section{Acknowledgments}

Funding: This study was financially supported by the National Natural Science Foundation of China (Grant No. 81172905) and the Scholarship Council of Shanxi Province (Grant No. 2015-050).

\section{Footnote}

Reporting Checklist: The authors have completed the STROBE Reporting Checklist. Available at http://dx.doi. org/10.21037/apm-20-89

Data Sharing Statement: Available at http://dx.doi. org/10.21037/apm-20-89

Conflicts of Interest: All authors have completed the ICMJE uniform disclosure form (available at http://dx.doi. org/10.21037/apm-20-89). The authors have no conflicts of interest to declare.

Ethical Statement: The authors are accountable for all aspects of the work in ensuring that questions related to the accuracy or integrity of any part of the work are appropriately investigated and resolved. The study protocol was carried out according to the Declaration of Helsinki (as revised in 2013). The research project was approved by the Ethics Committee of the Shanxi Provincial People's Hospital (No. 0000630). All applicable international, national, and/or institutional guidelines for the care and use of animals were followed.

Open Access Statement: This is an Open Access article distributed in accordance with the Creative Commons Attribution-NonCommercial-NoDerivs 4.0 International License (CC BY-NC-ND 4.0), which permits the noncommercial replication and distribution of the article with the strict proviso that no changes or edits are made and the original work is properly cited (including links to both the formal publication through the relevant DOI and the license). See: https://creativecommons.org/licenses/by-nc-nd/4.0/.

\section{References}

1. Yamamoto S, Yamane M, Yoshida O, et al. Early Growth Response-1 Plays an Important Role in Ischemia-Reperfusion Injury in Lung Transplants by Regulating Polymorphonuclear Neutrophil Infiltration. Transplantation 2015;99:2285-93.

2. Heiniger CD, Kostadinova RM, Rochat MK, et al. Hypoxia causes down-regulation of 11 beta-hydroxysteroid dehydrogenase type 2 by induction of Egr-1. FASEB J 2003;17:917-9.

3. Tarnavski O, McMullen JR, Schinke M, et al. Mouse cardiac 
surgery: comprehensive techniques for the generation of mouse models of human diseases and their application for genomic studies. Physiol Genomics 2004;16:349-60.

4. Myerburg RJ, Junttila MJ. Sudden cardiac death caused by coronary heart disease. Circulation 2012;125:1043-52.

5. Jing LX, Guo XJ, Jin QQ, et al. Basophil CD63 expression in the blood of the anaphylactic shock rat. Fa Yi Xue Za Zhi 2012;28:172-4, 178.

6. Hua W, Zhang LF, Wu YF, et al. Incidence of sudden cardiac death in China: analysis of 4 regional populations. J Am Coll Cardiol 2009;54:1110-8.

7. Thiel G, Cibelli G. Regulation of life and death by the zinc finger transcription factor Egr-1. J Cell Physiol 2002;193:287-92.

8. Yan SF, Fujita T, Lu J, et al. Egr-1, a master switch coordinating upregulation of divergent gene families underlying ischemic stress. Nat Med 2000;6:1355-61.

9. Tang S, Shi G. Egr-1 and myocardial ischemia-reperfusion injury. J Shantou Univ Med Coll 2004;4:225-8.

10. Zhang YM, Shi GG, Tang Z, et al. Effects of N-n-butyl haloperidol iodide on myocardial ischemia/reperfusion injury and Egr-1 expression in rat. Acta Biochim Biophys Sin 2006; 38:435-41.

11. Sun T, Zhang Y, Zhong S, et al. N-n-Butyl Haloperidol Iodide, a Derivative of the Anti-psychotic Haloperidol, Antagonizes Hypoxia/Reoxygenation Injury by Inhibiting an Egr-1/ROS Positive Feedback Loop in H9c2 Cells. Front Pharmacol 2018;9:19.

12. Mudaliar $\mathrm{H}$, Rayner $\mathrm{B}$, Billah $\mathrm{M}$, et al. Remote ischemic preconditioning attenuates EGR-1 expression following myocardial ischemia reperfusion injury through activation of the JAK-STAT pathway. Int J Cardiol 2017;228:729-41.

13. Zhou Y, Shi G, Zheng J, et al. The protective effects of Egr-1 antisense oligodeoxyribonucleotide on cardiac microvascular endothelial injury induced by hypoxiareoxygenation. Biochem Cell Biol 2010;88:687-95.

14. Lu S, Zhang Y, Zhong S, et al. N-n-butyl Haloperidol Iodide Protects against Hypoxia/Reoxygenation Injury in Cardiac Microvascular Endothelial Cells by Regulating the ROS/MAPK/Egr-1 Pathway. Front Pharmacol 2017;7:520.

15. Wang A, Zhang H, Liang Z, et al. U0126 attenuates ischemia/reperfusion-induced apoptosis and autophagy in myocardium through MEK/ERK/EGR-1 pathway. Eur J Pharmacol 2016;788:280-5.

16. Mudaliar H, Rayner B, Billah M, et al. Remote ischemic preconditioning attenuates EGR-1 expression following myocardial ischemia reperfusion injury through activation of the JAK-STAT pathway. Int J Cardiol 2017;228:729-41.
17. Lai L, Tang Y. Research progress of electroacupuncture and c-fos gene. Life Sci Res 2001;(S1):117-9.

18. Peng $X$, Tian W, Ping L, et al. Effects of $17 \beta$ - estradiol on myocardial ischemia-reperfusion injury in rats. Acta Anatomica Sinica 2009;40:807-10.

19. Zhang T, Zhou M, Wu S, et al. Effects of different intervention methods on c-fos gene expression in myocardial ischemia. World J Integr Tradit West Med 2013;8:630-2.

20. Ma M, Xu X. The application of protooncogene and protein of c-fos in forensic pathology. J Forensic Med 1999;(03):3-5.

21. Hu B, Chen Y, Zhu J, et al. A study of c-fos-mRNA in experimental early myocardial ischemia by in situ hybridization. Chin J Forensic Med 2000;(03):133-5.

22. Tsai YW, Yang YR, Wang PS, et al. Intermittent hypoxia after transient focal ischemia induces hippocampal neurogenesis and c-Fos expression and reverses spatial memory deficits in rats. PloS One 2011;6:e24001.

23. Pirzad Jahromi G, P Shabanzadeh A, Mokhtari Hashtjini $\mathrm{M}$, et al. Bone marrow-derived mesenchymal stem cell and simvastatin treatment leads to improved functional recovery and modified c-Fos expression levels in the brain following ischemic stroke. Iran J Basic Med Sci 2018;21:1004-12.

24. Chang NJ, Weng WH, Chang KH, et al. Genome-wide gene expression profiling of ischemia-reperfusion injury in rat kidney, intestine and skeletal muscle implicate a common involvement of MAPK signaling pathway. Mol Med Rep 2015;11:3786-93.

25. Huang C, Wang J, Wang N, et al. Effect of myocardial ischemic preconditioning on ischemia-reperfusion stimulation-induced activation in rat thoracic spinal cord with functional MRI. Int J Cardiol 2019;285:59-64.

26. Fox C, Walsh P, Mulhall KJ. Molecular Mechanism of Ischaemic Preconditioning of Skeletal Muscle In Vitro. Cureus 2018;10:e3763.

27. Santos MM, Tannuri AC, Coelho MC, et al. Immediate expression of c-fos and c-jun mRNA in a model of intestinal autotransplantation and ischemia-reperfusion in situ. Clinics (Sao Paulo) 2015;70:373-9.

28. Zhang S, Zhang M, Goldstein S, et al. The effect of c-fos on acute myocardial infarction and the significance of metoprolol intervention in a rat model. Cell Biochem Biophys 2013;65:249-55.

Cite this article as: Zhai LQ, Guo XJ, Li Z, Sun RF, Jin QQ, Liu MZ, Guo HL, Gao CR. Temporal changes in Egr-1 and c-fos expression in rat models of myocardial ischemia. Ann Palliat Med 2021;10(2):1411-1420. doi: 10.21037/apm-20-89 